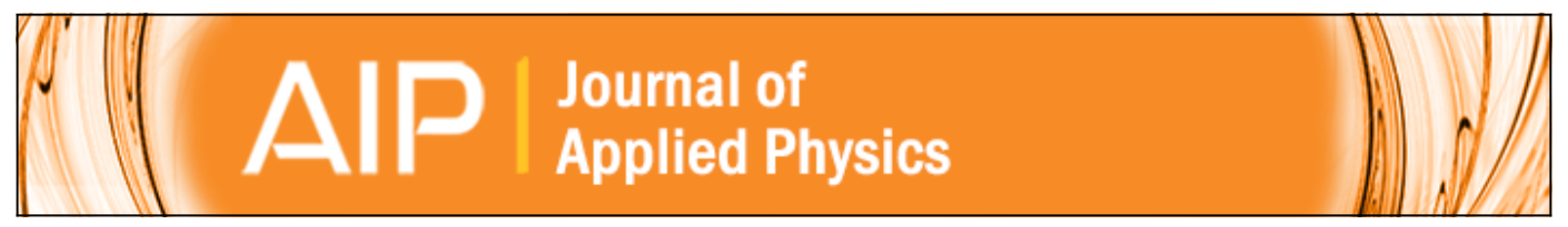

\title{
A comprehensive study of the influence of the stoichiometry on the physical properties of TiO $x$ films prepared by ion beam deposition
}

M. Claudia Marchi, Sara A. Bilmes, C. T. M. Ribeiro, E. A. Ochoa, M. Kleinke, and F. Alvarez

Citation: Journal of Applied Physics 108, 064912 (2010); doi: 10.1063/1.3481442

View online: http://dx.doi.org/10.1063/1.3481442

View Table of Contents: http://scitation.aip.org/content/aip/journal/jap/108/6?ver=pdfcov

Published by the AIP Publishing

\section{Articles you may be interested in}

Ion beam deposition of tantalum pentoxide thin film at room temperature

J. Vac. Sci. Technol. A 26, 991 (2008); 10.1116/1.2832407

Tailored stoichiometries of silicon carbonitride thin films prepared by combined radio frequency magnetron sputtering and ion beam synthesis

J. Vac. Sci. Technol. A 23, 1114 (2005); 10.1116/1.1946713

Structure and properties of carbon nitride thin films synthesized by nitrogen-ion-beam-assisted pulsed laser ablation

J. Vac. Sci. Technol. A 20, 1639 (2002); 10.1116/1.1496781

Effect of temperature on carbon nitride films synthesized by ion-beam-assisted pulsed laser deposition J. Appl. Phys. 88, 7060 (2000); 10.1063/1.1326474

Iron oxide thin films prepared by ion beam induced chemical vapor deposition: Structural characterization by infrared spectroscopy

J. Vac. Sci. Technol. A 18, 2244 (2000); 10.1116/1.1286198

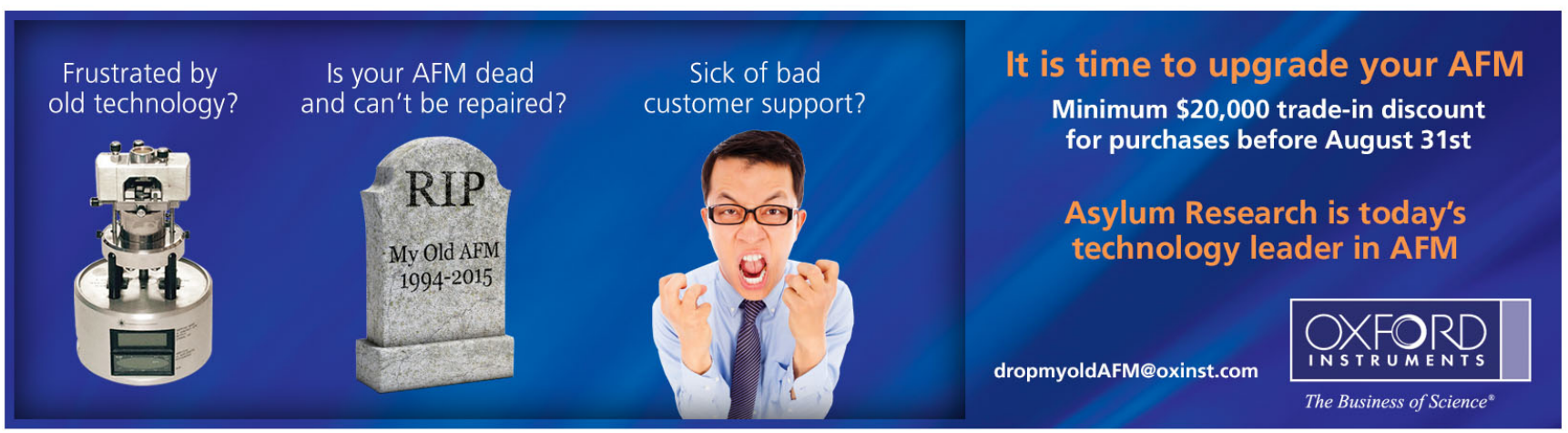




\title{
A comprehensive study of the influence of the stoichiometry on the physical properties of $\mathrm{TiO}_{x}$ films prepared by ion beam deposition
}

\author{
M. Claudia Marchi, ${ }^{1}$ Sara A. Bilmes, ${ }^{1}$ C. T. M. Ribeiro, ${ }^{2}$ E. A. Ochoa,${ }^{3}$ M. Kleinke, ${ }^{3}$ and \\ F. Alvarez ${ }^{3, a)}$ \\ ${ }^{1}$ INQUIMAE-DQIAyQF, Facultad de Ciencias Exactas y Naturales, Universidad de Buenos Aires, Ciudad \\ Universitaria, Pabellón II, C1428EHA Buenos Aires, Argentina \\ ${ }^{2}$ LTF, Instituto de Física, São Carlos, USP, P.O. Box 369, São Carlos 13560-250, Brazil \\ ${ }^{3}$ Instituto de Física Gleb Wataghin, UNICAMP, 13083-970 Campinas, São Paulo, Brazil
}

(Received 22 April 2010; accepted 26 July 2010; published online 28 September 2010)

\begin{abstract}
A comprehensive study of nonstoichiometry titanium oxide thin films $\left(\mathrm{TiO}_{x}, 0.3 \leq x \leq 2\right)$ prepared by ion beam deposition technique is reported. The physical properties of the material are studied by ultraviolet and x-ray photoelectron, Raman, and Fourier transform infrared spectroscopies, and atomic force microscopy. An abrupt transition from metallic characteristics to a wide gap semiconductor is observed in a very narrow range of oxygen variation. Concomitantly with this change the crystal structure and morphology suffer remarkable physical properties modifications. This transformation is ascribed to surface-volume energy minimization due to the influence of oxygen determining the size of the $\mathrm{TiO}_{2}$ particles during coalescence. (C) 2010 American Institute of Physics. [doi:10.1063/1.3481442]
\end{abstract}

\section{INTRODUCTION}

Titanium oxide has a wide range of applications such as pigments, catalysts, optical, coatings in human implants, and devices such as capacitors, sensors, metal-oxidesemiconductor transistors, and solar cells. ${ }^{1-10}$ The use of $\mathrm{TiO}_{2}$ powders or films is potentially important in the attempts to solve some environmental and energy problems. ${ }^{11}$ Moreover, $\mathrm{TiO}_{2}$ coatings improve surface hardness and wear resistance. ${ }^{12}$

$\mathrm{TiO}_{2}$ crystallizes in three different structures: rutile (tetragonal corner shared, space group $\mathrm{P}_{2} / \mathrm{mnm}$ ), anatase (tetragonal edge shared, space group $\mathrm{I}_{1} / \mathrm{amd}$ ), and the less common brookite (orthorhombic, space group Pbca). ${ }^{13}$ The $\mathrm{TiO}_{2}$ structure depends on the preparation method, conditions of synthesis, and thermal treatment. Rutile is the thermodynamically more stable phase and displays a relative high refraction index $\left(\mathrm{n}_{\mathrm{g}}=2.95\right) .{ }^{13}$ It is transparent in the visible and opaque in the ultraviolet range of the electromagnetic spectrum making the material appropriate for pigment applications. The anatase and brookite structures are transformed to rutile when properly heated. Anatase is chemically and optically active, suitable for catalyst support and photoelectrochemical material. ${ }^{14-16}$ Brookite is rare in nature. However, much interest was focused recently on this phase since it is electrochemically more active than anatase, thus becoming an interesting candidate for photovoltaic devices. ${ }^{17}$

The $\mathrm{TiO}_{2}$ films are produced by several methods such as hydrothermal, sol-gel, and by a variety of thin film deposition techniques. ${ }^{13,18}$ Among the latest techniques reactive evaporation, ${ }^{19}$ magnetron sputtering, ${ }^{20-23}$ chemical vapor deposition, ${ }^{24}$ and ion beam enhanced deposition, ${ }^{25}$ are the most common routes used for preparing uniform coatings, whereas solution pathways are preferred for catalysts appli-

${ }^{a)}$ Electronic mail: alvarez@ifi.unicamp.br. cations, where large areas are required. Also, it is well established that the physical properties of $\mathrm{TiO}_{2}$ films strongly depend on the oxygen content. ${ }^{13}$ Indeed, most of the preparation techniques involve the control of the oxygen partial pressure $\left(\mathrm{P}_{\mathrm{O}_{2}}\right)$ used during the material synthesis. However, the reported studies cover a narrow $\mathrm{P}_{\mathrm{O}_{2}}$ range making the comparison of results from different groups difficult. This limitation is particularly important near the phase transitions from rutile to anatase structures, where minute oxygen partial pressures completely change the result of the reaction. $^{21,22}$

In this paper we report a comprehensive study of the crystalline structure and morphology of $\mathrm{TiO}_{x}$ films obtained by ion beam deposition (IBD) in the range of $0.3<x<2$. The deposition method, using a Kaufman ion source, allows a precise control of both the ion current density and energy allowing a fine control of the physical properties of the $\mathrm{TiO}_{x}{ }^{26-29}$ The material was characterized by $\mathrm{x}$-ray (XPS) and ultraviolet (UPS) photoelectron emission spectroscopy, vibrational spectroscopy (Raman and Fourier transform infrared-FTIR), x-ray diffraction (XRD), and atomic force microscopy (AFM). The film thickness was measured by profilometry. The influence of the stoichiometry on the physical properties of the material is discussed.

\section{EXPERIMENTAL METHODS}

The $\mathrm{TiO}_{2}$ films were prepared by sputtering a high purity titanium target $(99.999 \%)$ in a high vacuum system (background pressure $\left.<2 \times 10^{-7} \mathrm{mbar}\right)$. The stoichiometry of the samples $(0.3<x \leq 2)$ was varied by changing the chamber oxygen partial pressure from the background pressure $\left(<10^{-7}\right.$ mbar $)$ up to $\sim 10^{-3}$ mbar. Rectangular 20 $\times 10 \mathrm{~mm}^{2}, 2 \mathrm{~mm}$ thick, polished crystalline silicon (111) wafers were used as substrates. The substrates were introduced in the deposition chamber after a standard cleaning 
TABLE I. Experimental data of as-deposited films under increasing oxygen pressure used in the chamber during the material growth: $x=\mathrm{O} / \mathrm{Ti}$ ratio, thickness, average grain size, and film color.

\begin{tabular}{|c|c|c|c|c|c|}
\hline Label & $\begin{array}{c}\mathrm{P}_{\mathrm{O}_{2}} \\
\text { (mbar) }\end{array}$ & $x=\mathrm{O} / \mathrm{Ti}$ & $\begin{array}{l}\text { Thickness } \\
(\mathrm{nm})\end{array}$ & $\begin{array}{l}\text { Size } \\
(\mathrm{nm})\end{array}$ & Color \\
\hline$a$ & $2.00 \times 10^{-8}$ & $0.31 \pm 0.02$ & $347 \pm 23$ & $83 \pm 4$ & Silver \\
\hline$b$ & $7.70 \times 10^{-7}$ & $0.71 \pm 0.05$ & $358 \pm 21$ & $71 \pm 9$ & Silver \\
\hline$c$ & $2.40 \times 10^{-6}$ & $0.60 \pm 0.04$ & $341 \pm 9$ & $\ldots$ & Silver \\
\hline$d$ & $5.24 \times 10^{-6}$ & $0.81 \pm 0.06$ & $372 \pm 23$ & $53 \pm 5$ & Silver \\
\hline$e$ & $7.99 \times 10^{-6}$ & $0.82 \pm 0.06$ & $362 \pm 15$ & $43 \pm 5$ & Silver \\
\hline$f$ & $1.29 \times 10^{-5}$ & $0.86 \pm 0.06$ & $364 \pm 15$ & $43 \pm 7$ & Silver \\
\hline$g$ & $1.98 \times 10^{-5}$ & $1.2 \pm 0.1$ & $375 \pm 27$ & $\ldots$ & Silver \\
\hline$h$ & $2.98 \times 10^{-5}$ & $1.6 \pm 0.1$ & $394 \pm 7$ & $68 \pm 10$ & Silver/gold \\
\hline$i$ & $3.08 \times 10^{-5}$ & $1.8 \pm 0.1$ & $412 \pm 16$ & $81 \pm 6$ & Gold \\
\hline$j$ & $4.08 \times 10^{-5}$ & $1.8 \pm 0.1$ & $466 \pm 26$ & $59 \pm 4$ and $81 \pm 8$ & Gold/orange \\
\hline$k$ & $5.09 \times 10^{-5}$ & $2.1 \pm 0.2$ & $181 \pm 17$ & $37 \pm 4$ and $71 \pm 11$ & Green \\
\hline$l$ & $7.99 \times 10^{-5}$ & $1.9 \pm 0.1$ & $137 \pm 22$ & $\ldots$ & Purple \\
\hline$m$ & $9.95 \times 10^{-5}$ & $1.9 \pm 0.1$ & $123 \pm 9$ & $46 \pm 4$ & Purple/yellow \\
\hline$n$ & $3.00 \times 10^{-4}$ & $2.1 \pm 0.2$ & $103 \pm 9$ & $39 \pm 6$ and $62 \pm 8$ & Yellow \\
\hline$o$ & $5.00 \times 10^{-4}$ & $1.9 \pm 0.1$ & $92 \pm 12$ & $21 \pm 6$ & Yellow \\
\hline$p$ & $8.00 \times 10^{-4}$ & $1.9 \pm 0.1$ & $103 \pm 9$ & $\ldots$ & Yellow \\
\hline$q$ & $1.00 \times 10^{-3}$ & $1.8 \pm 0.1$ & $96 \pm 26$ & $17 \pm 2$ & Yellow \\
\hline
\end{tabular}

procedure (ultrasound in chemical detergent, acetone rinsing, and drying by blowing nitrogen). The distance between the target and the substrate holder was maintained constant $(160$ $\mathrm{mm}$ ) for all the prepared samples. All the samples were deposited maintaining the substrate temperature constant $(407 \pm 2){ }^{\circ} \mathrm{C}$ during $60 \mathrm{~min}$.

The deposition chamber is attached to an ultra high vacuum chamber for photoelectron spectroscopy analysis (UPS, XPS), i.e., the samples are not atmospheric contaminated. The deposition chamber contains a dc Kaufman cell that can be operated from $\sim 30$ to $1000 \mathrm{eV}$ and up to $2 \mathrm{~mA} / \mathrm{cm}^{2}$ according to the experiment requirements. Details of the system are reported elsewhere. ${ }^{28,30}$ Structural parameters (ex situ) were derived from vibrational spectroscopy (Raman, FTIR) and XRD. Micro-Raman ( $\mu$-Raman) (spot size $\sim 0.8 \mu \mathrm{m}^{2}, \sim 700 \mu \mathrm{W}, \sim 2 \mathrm{~cm}^{-1}$ resolution) spectra were obtained in a backscattering configuration by exciting the sample with the $632.8 \mathrm{~nm} \mathrm{He}-\mathrm{Ne}$ line ( $\mu$-Raman, Renishaw RM 2000 setup). The Raman Si signal from the substrate was properly subtracted. Infrared spectra were performed with a Nicolet, Magna-IR 760 spectrometer FTIR $\left(4 \mathrm{~cm}^{-1}\right.$ resolution). XRD patterns were obtained at low incident angle $\left(2^{\circ}\right)$ with a Rigaku Rotaflex RU 200B device $(\mathrm{Cu} K \alpha$ radiation, $\lambda=1.54 \AA$, $\mathrm{U}=50 \mathrm{keV}$, and $\mathrm{I}$ $=100 \mathrm{~mA}$ ), operating in the continuous scan mode at $1 \% \mathrm{~min}$ and $0.02^{\circ}$ steps. Crystalline domain sizes were estimated from Scherrer equation ${ }^{31}$ assuming that the particles are spherical, and the structure factor is 0.9 .

Once deposited, the sample is transferred to the UHV chamber and the UPS and XPS spectra immediately recorded. The He-I and He-II lines $(h \nu=21.2 \mathrm{eV}$ and $40.8 \mathrm{eV}$, respectively) or $\mathrm{Al} K \alpha$ line $(h \nu=1486.6 \mathrm{eV})$ are used as excitation sources in photoelectron emission spectroscopy (UPS, XPS). A VG-CLAMP-2 electron analyzer combined with the excitation line width gives a total resolution of $\sim 0.3 \mathrm{eV}$ and $1.2 \mathrm{eV}$ for UPS and XPS, respectively. The UPS spectra thus obtained represent the energy distribution joint density of states (EDJDOS) of the valence and conduction bands properly weighted by the matrix electron transition probability. ${ }^{32,33}$ The electron binding energies (BEs) are referred to the Fermi level $E_{F}$ as determined from the photoelectron spectrum obtained in a silver sample properly cleaned by sputtering. Quantitative analysis of XPS spectra was performed after subtraction of the inelastic background using Shirley's method. ${ }^{34}$ The atomic composition $(\mathrm{O}$ and $\mathrm{Ti})$ was determined by integrating the core level peaks, weighted by the corresponding photoemission cross-section. ${ }^{35}$ The $\mathrm{O}$ and $\mathrm{Ti}$ oxidation of symmetric bands states were determined by fitting the spectra with multiple Gaussians curves. In this case asymmetric bands Gaussian-Lorentzian curves were used. The surface morphology was analyzed by AFM (AutoProbe CP, Park Scientific Instruments) operating in noncontact mode under atmospheric condition. AFM scans were made over areas of $5 \times 5 \mu \mathrm{m}^{2}, 3 \times 3 \mu \mathrm{m}^{2}, 1 \times 1 \mu \mathrm{m}^{2}$, and $0.8 \times 0.8 \mu \mathrm{m}^{2}$ with a resolution of $516 \times 516$ pixels. Finally, the thickness of the films was measured with a Dektak3 profilometer from the step produced by a suitable shaded region of the substrate during the sample deposition.

\section{RESULTS: ANALYSIS OF THE EXPERIMENTAL DATA}

The different techniques used in the material characterization provide information on the physical properties dependence on the composition and deposition conditions of the samples. Table I summarizes the atomic composition, thickness, median grain size, and color for the studied samples for each oxygen partial pressure $\left(\mathrm{P}_{\mathrm{O}_{2}}\right)$ used during the material deposition. We shall pay special attention to the important physical changes observed in the $2 \times 10^{-8}$ to $1 \times 10^{-3} \mathrm{mbar}$ oxygen partial pressure range. For the sake of clarity each physical property of the material will be analyzed separately. 

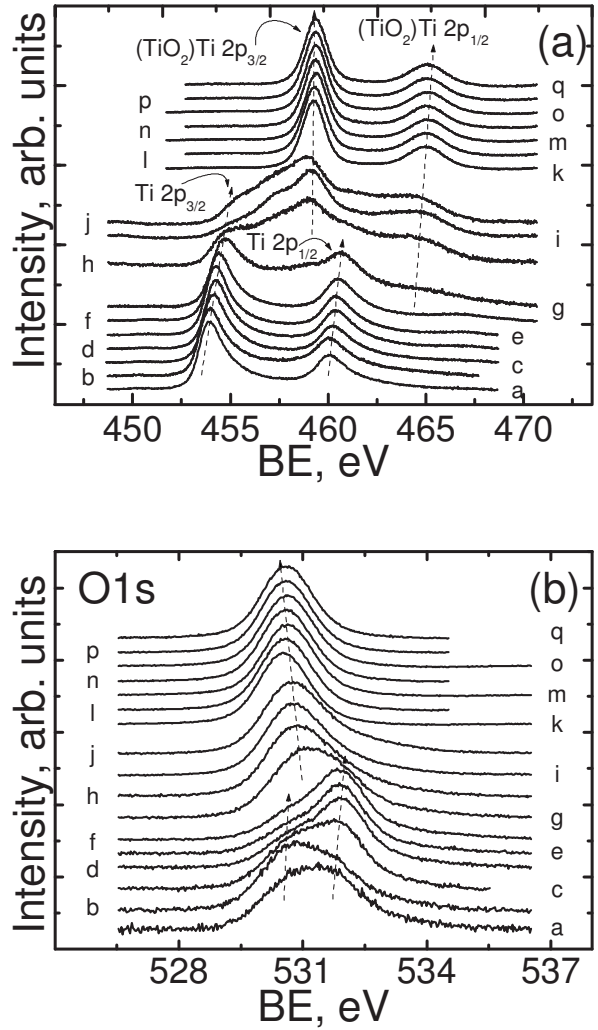

FIG. 1. XPS normalized spectra for the (a) Ti $2 p$ and (b) $\mathrm{O} 1 s$ electron core level of thin films prepared by IBD under increasing oxygen partial pressure (substrate temperatures: $407^{\circ} \mathrm{C}$ ). The oxygen pressures used for growing the samples are indicated in Table I.

\section{A. Chemical composition and electronic structure}

Figure 1(a) shows the evolution of XPS spectra corresponding to the Ti $2 p$ electron core levels. The identification label on each curve corresponds to the data reported in Table I. In all spectra the characteristic features associated with the Ti $2 p_{3 / 2}$ and $\mathrm{Ti} 2 p_{1 / 2}$ core electrons are recognized.

Two families of curves are distinguished. The first one (curves $a$ to $f$ ) with bands located at $\sim 454$ ( Ti 2p $p_{3 / 2}$ ) and $460 \mathrm{eV}\left(\mathrm{Ti} 2 p_{1 / 2}\right)$ is characteristic of metallic Ti. The subtle shift in Ti $2 p$ peaks to higher energies as $\mathrm{P}_{\mathrm{O}_{2}}$ raises indicates an increase in oxidized Ti species (indicated by dashed arrows). The second family (curves $k$ to $q$ ) is obtained for $\mathrm{P}_{\mathrm{O}_{2}}>5 \times 10^{-5}$ mbar. In these spectra Ti $2 p$ peaks are located at $\sim 458.8$ and $\sim 464.5 \mathrm{eV}$, which correspond to $\mathrm{Ti}^{4+}$ in $\mathrm{TiO}_{2}$ structures. ${ }^{36,37}$ Between these well defined phases there is a narrow oxygen partial pressure window where spectra show several broad peaks and shoulders. In addition to $\mathrm{Ti}^{0}$ and $\mathrm{Ti}^{4+}$ species, by fitting multiple GaussianLorentzian or Gaussian curves ${ }^{38}$ new bands are identified. Indeed, bands located at $\sim 455.0 \mathrm{eV}$ and $\sim 460.8 \mathrm{eV}$ and at $\sim 456.9 \mathrm{eV}$ and $\sim 462.7 \mathrm{eV}$ can be ascribed to $\mathrm{Ti}^{2+}$ in $\mathrm{TiO}$ and $\mathrm{Ti}^{3+}$ in $\mathrm{Ti}_{2} \mathrm{O}_{3}$ structures, respectively.

Figure 1(b) shows the normalized XPS spectra of O 1 s electronic core levels. This band shifts to lower BE when the material becomes richer in oxygen. For curves $k$ to $q$ there is a unique symmetric band centered at $\sim 530.6 \mathrm{eV}$ corresponding to $\mathrm{O}^{2-}$ in $\mathrm{Ti}^{4+}-\mathrm{O}$ bonds. ${ }^{39}$ In the other hand, at lower $\mathrm{P}_{\mathrm{O}_{2}}$ values, this band becomes broader, asymmetric,
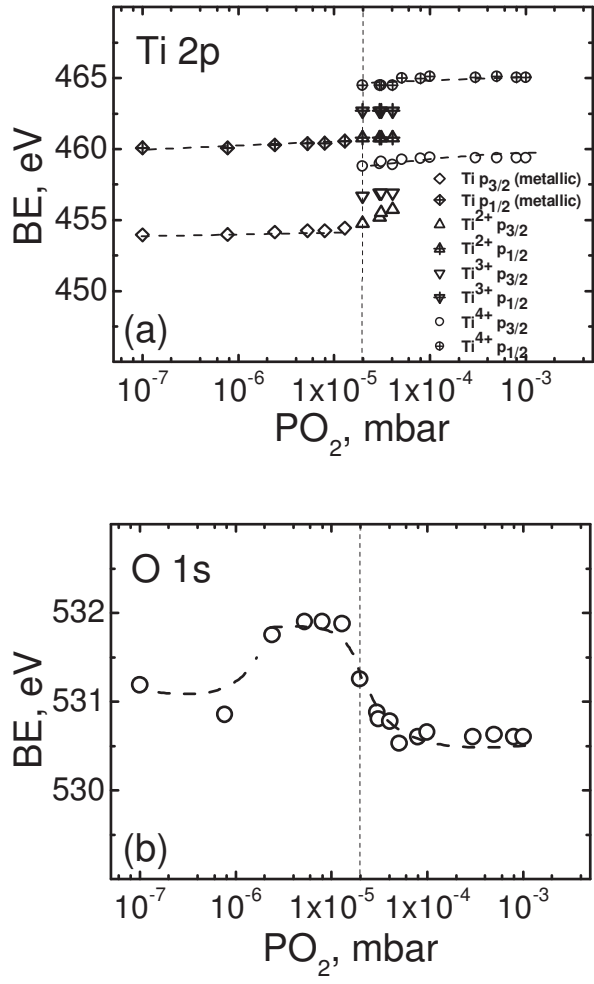

FIG. 2. Variation on the energy associated with the position of (a) Ti $2 p$ and (b) O $1 s$ XPS core level electrons for samples deposited at different oxygen pressures. The symbols correspond to Ti $2 p_{3 / 2}$ band: $(\diamond) \mathrm{Ti}^{4+}$ in metallic titanium, $(\triangle) \mathrm{Ti}^{2+}$ in $\mathrm{TiO},(\nabla) \mathrm{Ti}^{3+}$ in $\mathrm{T}_{2} \mathrm{O}_{3}$, and $(O)$ for $\mathrm{Ti}^{4+}$ in $\mathrm{TiO}_{2}$; the doted symbols correspond to the electrons associated with the $2 p_{1 / 2}$ core levels.

and a shoulder at lower energies is defined. These features are characteristic of different oxygen bonds and can be identified using the same fitting procedure employed above. The presence of adsorbed $\mathrm{O}_{2}{ }^{2-}$ (peroxide) and $\mathrm{O}_{2}^{-}$(superoxide) with maximum $\mathrm{BE}$ at $\sim 531 \mathrm{eV}$ and $532 \mathrm{eV}$, respectively predominant. ${ }^{6,40}$ These species, as well as $\mathrm{O}^{-}$, are formed by adsorption of $\mathrm{O}_{2}$ onto reduced surfaces. ${ }^{41}$ Curves $a$ and $b$, at lowest $\mathrm{P}_{\mathrm{O}_{2}}$ can be assigned to physisorbed $\mathrm{O}_{2}$ to a monolayer or less of chemisorbed $\mathrm{O}$ for which a lower $\mathrm{BE}$ is expected. Figure 2(a) displays the evolution of the band position associated with the Ti $2 p\left(2 p_{3 / 2}\right.$ and $\left.2 p_{1 / 2}\right)$ electrons as a function of the oxygen partial pressure. From this plot it is clear that the ill-defined intermediate region is a convolution of $\mathrm{Ti}$ species with all possible oxidation states. Similarly, Fig. 2(b) shows the behavior of the band associated with the $\mathrm{O} 1 \mathrm{~s}$ electron core level of the sample.

As described in Sec. II, the stoichiometry of the oxide was obtained from XPS spectra by appropriate integration of Ti $2 p$ and $\mathrm{O} 1 s$ plots. The resulting values, $x$, are presented in Table I and for the sake of clarity, plotted against $\mathrm{P}_{\mathrm{O}_{2}}$ in Fig. 3. For $x<1.24$ the XPS spectra reveal the presence of metallic titanium. In the transition region $(1.24<x<1.81)$ the spectra indicate titanium in $\mathrm{Ti}^{2+}, \mathrm{Ti}^{3+}$, and $\mathrm{Ti}^{4+}$ electronic states of oxidation. Finally, for $x>1.81$ the Ti $2 p$ electrons are occupying $\mathrm{Ti}^{4+}$ in $\mathrm{TiO}_{2}$ structures. Figures 4(a) and 4(b) show the EDJDOS evolution for different $\mathrm{P}_{\mathrm{O}_{2}}$ pressures obtained by UPS and using the He-I and $\mathrm{He}-\mathrm{II}$ lines, respectively. These spectra are characteristic of titanium oxide 


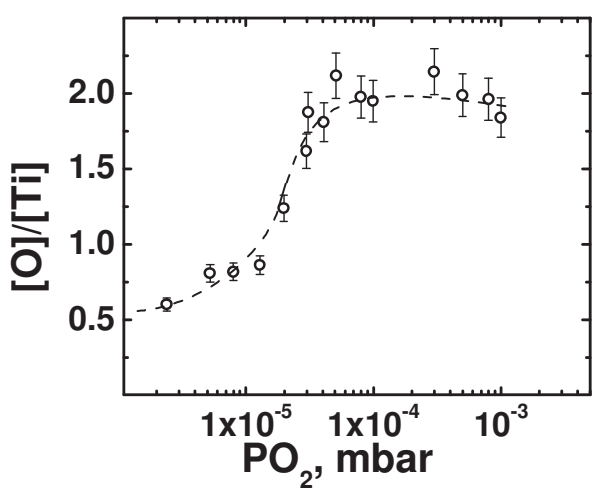

FIG. 3. Evolution of $x=\mathrm{O} / \mathrm{Ti}$ ratio (Table I) obtained by XPS from samples deposited at different oxygen partial pressures. Error bars indicate the standard deviation of the measures and the dashed line is a guide for the eyes.

compounds and the features located at $\sim 3-9 \mathrm{eV}$ are due to O $2 p$ orbital. $^{42}$ Similar features are observed in Figs. 4(a) and $4(\mathrm{~b})$. We note that the background due to inelastic electron scattering is stronger in the spectra obtained with He-I photons than with He-II. This is evident from the fact that the use of He-II photons enhances the structure observed near $\sim 4 \mathrm{eV}$, a feature ascribed to surface states ${ }^{42}$ on the basis of the escape depth of photoelectrons $(\sim 5 \AA$ for He-II and 10-15 $\AA$ for He-I) ${ }^{32,40,43}$ A narrow band near to $E_{F}$ is well defined in curves $a$ to $g$, i.e., for $\mathrm{P}_{\mathrm{O}_{2}}<1.98 \times 10^{-5}$ mbar.

The EDJDOS is clearly composed by two bands (labeled $\mathrm{A}$ and B) for $x<0.86$ (curves $a$ to $f$ ). For near stoichiometric oxides a new band merges (labeled D), and the onset of the valence band shifts to lower energies. This triplet structure is
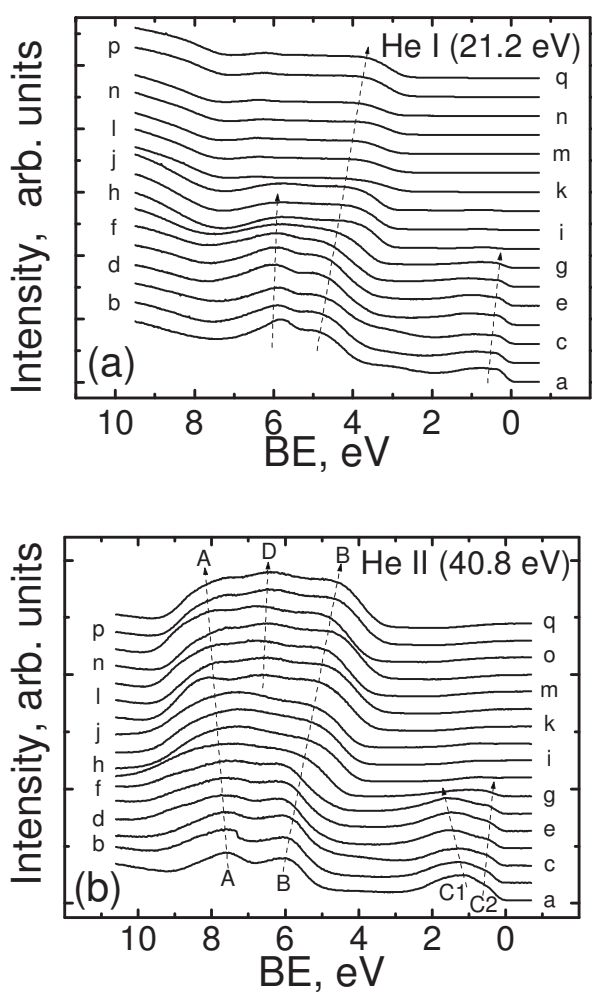

FIG. 4. UPS spectra of the samples prepared by IBD at different oxygen partial pressures (Table I, substrate temperatures: $407^{\circ} \mathrm{C}$ ) for (a) He-I and (b) He-II UV radiation source. The spectra have been normalized by the O $2 p$ intensity band.

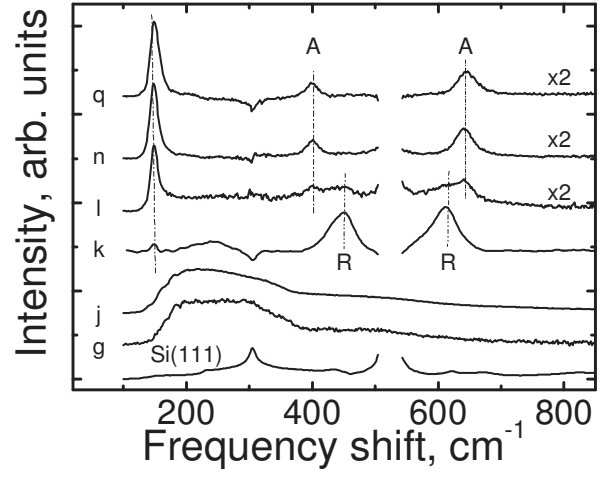

FIG. 5. Raman spectra of the samples prepared at different oxygen partial pressures (Table I). For comparison purposes, the spectrum of the substrate is indicated.

characteristic of reconstructed and faceted $\mathrm{TiO}_{2}$ surfaces. ${ }^{42}$ Indeed, peaks $\mathrm{A}$ and $\mathrm{B}$ correspond to $\sigma$ bond resulting from $\mathrm{O} 2 p$-Ti $\mathrm{e}_{\mathrm{g}}$ orbital overlapping and peak $\mathrm{D}$ to $\pi$ bonds from O $2 p$ - $\mathrm{Ti}_{2 \mathrm{~g}}$ orbital overlapping. ${ }^{44}$ The latter is sensitive to surface containing oxygen bonding bonds, i.e., geometries deviating from those found in bulk $\mathrm{TiO}_{2}{ }^{42,43}$

The higher density of states (EDJDOS) near $E_{F}$ for samples concentrations in the range $0.31<x<0.86$ (band C), is characteristic of a metallic material with partially filled Ti $3 d$ states $^{42}$ which becomes negligible for $x>1.62$. It is interesting to note that the EDJDOS decreases near $E_{F}$ and it is accompanied by an $\mathrm{O} 2 p$ band shift to lower BE values.

\section{B. Structure dependence on the material composition}

Representative Raman spectra of the studied samples are displayed in Fig. 5. As expected, Raman spectra are featureless for $x<1.24$ due to the metallic character of samples (not shown). On the other hand, curves $g$ and $\mathrm{j}$ have Raman spectra characteristic of amorphous titanium oxides with multiple peaks in the $170-400 \mathrm{~cm}^{-1}$ range arising from second order scattering process. ${ }^{45}$ The curve identified as $k$ shows three of the four Raman modes characteristic of rutile structures, i.e., two intense bands at $\sim 446\left(\mathrm{E}_{\mathrm{g}}\right)$ and $607 \mathrm{~cm}^{-1}\left(\mathrm{~A}_{1 \mathrm{~g}}\right)$, and a weaker band at $\sim 143 \mathrm{~cm}^{-1}\left(\mathrm{~B}_{1 \mathrm{~g}}\right){ }^{46}$ In order to have better discrimination of the other bands, the fourth mode at $\sim 827 \mathrm{~cm}^{-1}\left(\mathrm{~B}_{2 \mathrm{~g}}\right)$ is omitted in Fig. 5. The broad multiple peaks at $\sim 239 \mathrm{~cm}^{-1}$ indicate the presence of amorphous contributions which correspond to a second order scattering process. ${ }^{45}$ On the other hand, for the curve $l$ the spectrum shows traces of the rutile phase and three of the six fundamental Raman active modes characteristic of anatase structures located at $\sim 148\left(\mathrm{E}_{\mathrm{g}}\right), \sim 401\left(\mathrm{~B}_{1 \mathrm{~g}}\right)$, and $640 \mathrm{~cm}^{-1}\left(\mathrm{E}_{\mathrm{g}}\right){ }^{45,46}$ Other expected modes, such as $\mathrm{A}_{1 \mathrm{~g}}$ and $\mathrm{B}_{1 \mathrm{~g}}$, at $\sim 518 \mathrm{~cm}^{-1}$ are masked by the signal of silicon substrate. All spectra recorded with samples deposited with $\mathrm{P}_{\mathrm{O}_{2}}>9.95 \times 10^{-5}$ mbar are unambiguously compatible with anatase crystalline structures.

Figure 6 shows representative FTIR spectra of samples with $x \sim 2$. These spectra have two bands located at $\sim 500 \mathrm{~cm}^{-1}, \sim 445 \mathrm{~cm}^{-1}$, as well as an ill-defined structure at $\sim 700 \mathrm{~cm}^{-1}$. The dominant feature centered at $\sim 500 \mathrm{~cm}^{-1}$ is assigned to $\mathrm{E}_{\mathrm{u}}$ mode corresponding to the 


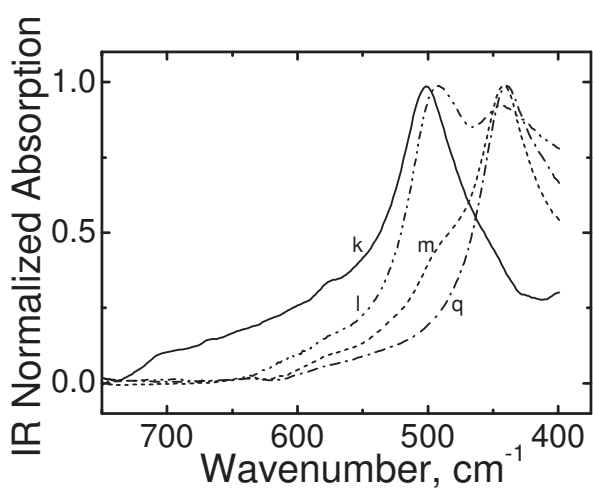

FIG. 6. FTIR absorption spectra of the samples obtained at normal incidence, deposited at different oxygen partial pressures (Table I).

$\mathrm{Ti}-\mathrm{O}$ stretching in rutile structures (curve $k$ ) (Refs. 39 and 46) and the band at $\sim 445 \mathrm{~cm}^{-1}$ is attributed to $\mathrm{Ti}-\mathrm{O}$ band in anatase crystalline phase. ${ }^{47,48}$ Consistent with the Raman results, for higher oxygen content (curve $m$ ) the band associated with $\mathrm{Ti}-\mathrm{O}$ stretching in rutile structures is negligible, whereas that corresponding to anatase (curve $q$, $\sim 439 \mathrm{~cm}^{-1}$ ) dominates the whole spectrum. ${ }^{47}$ In both rutile and anatase structures the oxygen ions link three Ti ions with $\mathrm{C}_{2 \mathrm{v}}$ symmetry. Therefore, three independent vibration modes are expected with $A_{1}, B_{1}$, and $B_{2}$ symmetries. $B_{1}$ are out-ofplane modes while $A_{1}$ and $B_{2}$ combine the Ti-O stretching with those of $\mathrm{Ti}-\mathrm{O}-\mathrm{Ti}$ in-plane modes. However, these angles depend on the particular crystalline structure, i.e., 1 $\times 99^{\circ}$ and $2 \times 130.5^{\circ}$ for rutile and $1 \times 155^{\circ}$ and $2 \times 102^{\circ}$ for anatase phases, respectively. In the case of rutile the modes arising from $A_{1}$ and $B_{2}$ have predominantly the Ti-O stretching character and in-plane deformations, respectively. On the other hand, for anatase, the modes are completely mixed. ${ }^{46}$

We note that curves $k$ and $l$ show two particularities. First, there is an ill-defined band at $\sim 700 \mathrm{~cm}^{-1}$ that has been previously assigned to the formation of a non stoichiometric $\mathrm{TiO}_{x}$ with $x<2$ and special particle shapes. ${ }^{46,49}$ Second, the observed slight shift in the $500 \mathrm{~cm}^{-1}$ band toward a smaller wavenumber in sample $l$ is also related to changes in particle size effect. $^{39,46}$

Finally, we remark that the cleanliness of deposition method and analysis conditions are confirmed by the absence of bands associated with $\mathrm{OH}$ and $-\mathrm{CH},-\mathrm{CH}_{2}$ groups in the $\quad 3200-3800 \mathrm{~cm}^{-1}, \quad 2500-3600 \mathrm{~cm}^{-1}$, and 1400-2900 $\mathrm{cm}^{-1}$ regions (not shown), respectively. ${ }^{49}$

XRD experiments probe deeper parts of the samples than XPS measurements. Indeed, the diffractograms show a fine control of the material structure by dosing the oxygen gas

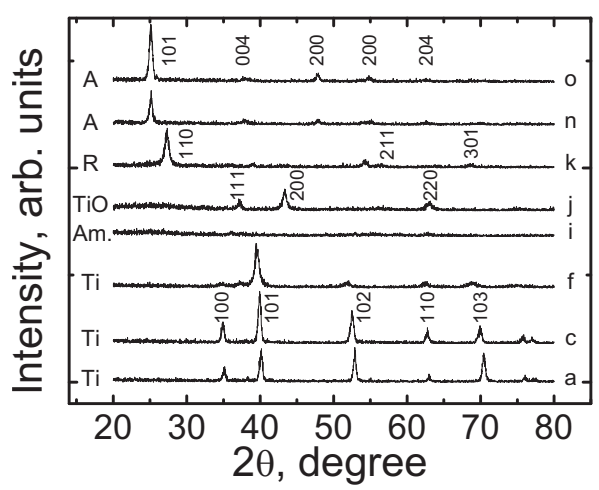

FIG. 7. X-ray diffractograms obtained by small incident angle of asdeposited $\mathrm{TiO}_{x}$ samples. The oxygen partial pressures used during the deposition are indicated in Table I.

pressure bleeding into the chamber (Fig. 7). Confirming the above results (Sec. II), samples with $x<0.86$ show diffraction patterns consistent with metallic titanium having preferred orientations (101), (102) and (103) (curves $a, c$, and $f)$. Increasing oxygen content decreases the metallic character of the diffractograms. For $\mathrm{P}_{\mathrm{O}_{2}} \sim 3.08 \times 10^{-5}$ mbar, the material becomes amorphous, with incipient rutile formation. Further oxygen addition induces crystalline $\mathrm{TiO}$ formation, with (200), (111), and (220) x-ray preferred plane reflections (curve $j$ ). Also, the curve shows an incipient peak associated with $\mathrm{TiO}_{2}$ rutile that establishes definitively in diffractogram $k$, with the (110) preferred orientation. Finally, further increasing the oxygen partial pressure in the chamber the structure changes to stoichiometry $\mathrm{TiO}_{2}$ (anatase) and (101) preferred orientation (curves $n$ and $q$ ). It is interesting to note that the full-width at half-maximum (FWHM) of all the peaks observed in the XRD is very narrow $\left(\sim 0.5^{\circ}\right.$ mean value), suggesting the formation of fine crystalline $\mathrm{TiO}_{2}$ material. The crystallite domain size $D$ of the formed crystallite can be estimated by the Scherrer equation. ${ }^{31}$ The obtained $D$ values for the preferential grown orientation are listed in Table II.

\section{Thickness and morphology dependence on the material composition}

The central plot in Fig. 8 shows the thickness $t$, of the as-deposited $\mathrm{TiO}_{x}$ thin films. It is found that the films synthesized at different $\mathrm{O}_{2}$ chamber pressures exhibit an abrupt thickness dependence on $\mathrm{P}_{\mathrm{O}_{2}}$. For $\mathrm{P}_{\mathrm{O}_{2}}<1.98 \times 10^{-5}$ mbar, $375 \leq t \leq 341 \mathrm{~nm}$ with a mean thickness of $\langle t\rangle$ $=359 \pm 13 \mathrm{~nm}$ whereas for $\mathrm{P}_{\mathrm{O} 2} \geq 9.95 \times 10^{-5}$ mbar $92 \leq t$ $\leq 123 \mathrm{~nm}$, with $\langle t\rangle=103 \pm 12 \mathrm{~nm}$. In the intermediate narrow range $1.98 \times 10^{-5}<\mathrm{P}_{\mathrm{O} 2}<4.08 \times 10^{-5}$ mbar, $t$ grows up

TABLE II. Crystalline structure (Ti: metallic titanium, R: rutile phase, $\mathrm{TiO}_{2}, \mathrm{~A}$ : anatase phase, $\mathrm{TiO}_{2}$ ), preferential orientation and crystallite domain size $D$ obtained from XRD for the studied films ( $D$ is determinate by the Scherrer equation using the preferential orientation peak).

\begin{tabular}{lccccccc}
\hline \hline Curve & $a$ & $c$ & $f$ & $j$ & $k$ & $n$ & $q$ \\
\hline Structure & $\mathrm{Ti}$ & $\mathrm{Ti}$ & $\mathrm{Ti}$ & $\mathrm{TiO}$ & $\mathrm{R}$ & $\mathrm{A}$ & $\mathrm{A}$ \\
Orientation & $(101)$ & $(101)$ & $(101)$ & $(200)$ & $(110)$ & $(101)$ & $(101)$ \\
$\mathrm{D} \pm 1(\mathrm{~nm})$ & 19 & 19 & 12 & 15 & 11 & 17 & 16 \\
\hline \hline
\end{tabular}




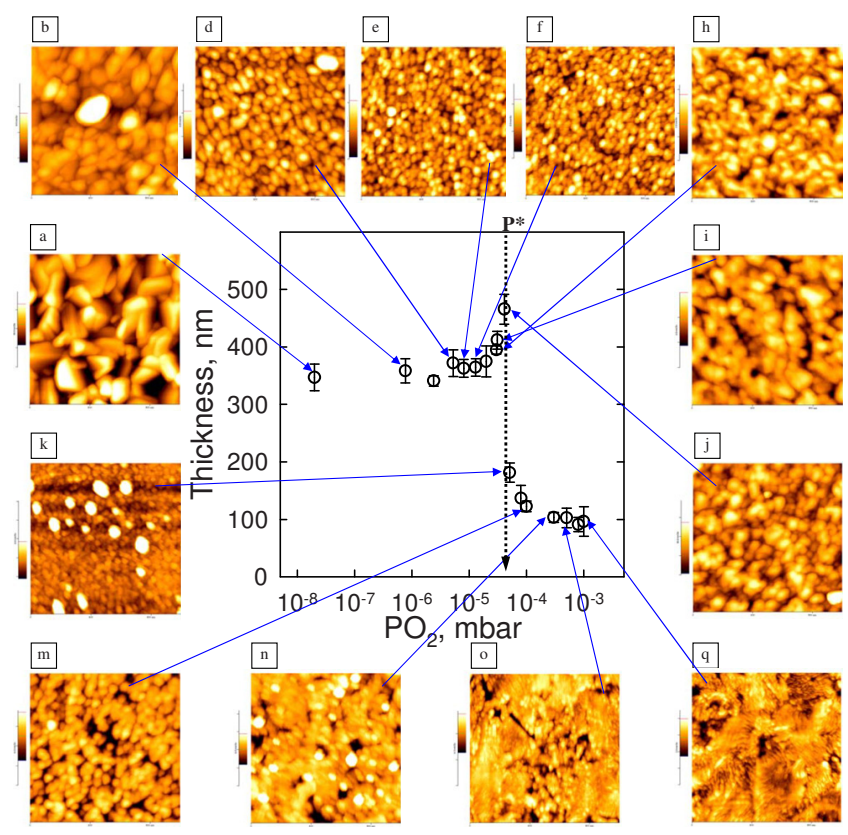

FIG. 8. (Color online) AFM images $\left(1 \times 1 \mu \mathrm{m}^{2}\right)$ of the films deposited at different oxygen partial pressures (Table I). The central plot shows the thickness of the films. The error bars represent the standard deviation of different measures realized in several sites of the studied sample. $\mathrm{P}^{*}$ point out the oxygen partial pressure value where the physical properties of the material change.

to $466 \mathrm{~nm}$ followed by an abrupt decay up to $92 \mathrm{~nm}$. Above a characteristic $\mathrm{P}_{\mathrm{O}_{2}}\left(\mathrm{P}^{*}=4.5 \times 10^{-5}\right.$ mbar $)$ there is discontinuity in the thickness and within the experimental error, the stoichiometry of the films produced above $\mathrm{P}^{*}$ are similar.

The morphology evolution of the samples strongly depends on the compound stoichiometry. Similar topography was found by AFM in experiments probing several areas sizes of the studied samples $\left(\sim 0.64,1,9,25 \mu \mathrm{m}^{2}\right)$. For sake of clarity, however, only pictures obtained in $1 \mu \mathrm{m}^{2}$ areas are depicted in Fig. 8. The median grain size of each sample was determined from the pictures and is reported in Table I.

Films deposited at $\mathrm{P}_{\mathrm{O}_{2}} \approx 2 \times 10^{-8}$ mbar show isolated grain size around $\sim 83 \mathrm{~nm}$ with irregular shape (sample $a$, Fig. 8). Small oxygen incorporation induces changes in the material morphology, rounding the grains boundaries and giving less compact films with $\sim 71 \mathrm{~nm}$ grains mean size (sample $b$ ). Near to the abrupt stoichiometric changes at $x$ $\sim 0.8$, the grain size is smaller $(\sim 53 \mathrm{~nm}$ in $d, \sim 43 \mathrm{~nm}$ in $e$ and $f$ ) with a coalescing trend in the transition region itself. A formation of cluster is more evident in pictures $h$ and $i$ where the particles size range from $\sim 68$ to $\sim 81 \mathrm{~nm}$. Image $j$ displays a distribution of two particles size $(\sim 59$ and $\sim 81 \mathrm{~nm}$ ). The particles size going to diminished up to sample $n$. Finally the formation of almost continuous and compact films is established in samples $o$ and $q$, i.e., after the stoichiometric $\mathrm{TiO}_{2}$ formation.

\section{DISCUSSION}

The results presented in the previous sections show a subtle control of the properties of $\mathrm{TiO}_{x}$ in a broad range of oxygen partial pressure. An abrupt jump in the film properties occurs in a narrow oxygen partial pressure around $\mathrm{P}_{\mathrm{O}_{2}}$ $\sim 4.5 \times 10^{-5}$ mbar, Fig. 3, i.e., for $\sim 0.8<x<2$. This particular oxygen partial pressure will be labeled $\mathrm{P}^{*}$. For the sake of clarity we organize this section analyzing the processes leading to film properties in three defined composition ranges: (i) $x<1$; (ii) $1<x<2$, and (iii) $x \sim 2$.

In the $x<1$ range, the films are formed by a collection of particles composed of Ti clusters having a metallic character, as shown by the band electronic structure near the Fermi level (Fig. 4). This band is similar to the one reported in $\mathrm{TiO}_{0.93}$ and $\mathrm{TiO}_{1.15}$ (Ref. 50) and it is composed of two contributions: (1) the main one at $\sim 1 \mathrm{eV}$ from Ti $3 d$ metallic orbitals; (2) the contribution at lower energies corresponding to contributions from surface states. As remarked in Sec. III, the metallic properties of the films obtained in this pressure range are further confirmed by the lack of features in the Raman and FTIR spectra.

The morphology of films obtained at the lowest deposition oxygen pressure shows pores embedded in a disordered structure. We point out that the presence of adsorbed oxygen cannot be ruled out. Indeed, $\mathrm{Ti}$ is highly exergonic and even at very low $\mathrm{P}_{\mathrm{O}_{2}}$ the surface could be covered by absorbed $\mathrm{O}$ atoms. This oxide monolayer can support further oxygen adsorption, and to a lesser extent, $\mathrm{O}_{2}{ }^{-}$or $\mathrm{O}_{2}{ }^{2-}$ species as it has been demonstrated for oxygen adsorption on rutile single crystals. ${ }^{13,42,51}$ Moreover, oxygen chemisorptions implies the formation of a $\mathrm{Ti}-\mathrm{O}$ bond at the surface with considerable chemical shift. This conclusion is reinforced by the fact that the latter effect shifts the $\mathrm{O} 1 \mathrm{~s} \mathrm{BE}$ to higher values $(\sim 532 \mathrm{eV})$ than those expected in $\mathrm{Ti}^{4+}-\mathrm{O}^{2-}$ complex, i.e., in structures where oxygen is bound to $\mathrm{Ti}$ ions in an octahedral environment $(\sim 530 \mathrm{eV})$. Moreover, the films with $x<1$ analyzed by XRD exhibit patterns of metallic Ti (Fig. 7, samples $a, c, f$ ) supporting the assumption that the band at $\sim 532 \mathrm{eV}$ in the XPS spectra probably arises from oxygen at the surface.

On the one hand, at low deposition oxygen partial pressures the $\mathrm{Ti}$ atoms arriving at the $\mathrm{Si}$ substrate are relatively free to wander onto the surface. Thus, nucleation will be controlled by diffusion mechanism leading to the formation of metallic continuous films. On the other hand, higher oxygen partial pressure probably limits the formation of larger aggregates by the so-called ripening Ostwalt phenomenon, as seen in the AFM pictures (Fig. 8, samples $d, e, f){ }^{52,53}$ Indeed, the presence of large amounts of oxygen surrounding $\mathrm{Ti}$ atoms prevent particles interaction and thus coalescence of larger cluster.

For the region $1<x<2$, the atomic local structure of the material on oxygen incorporation is understood by following the band structure evolution. Indeed, the $\mathrm{Ti} 2 p$ and $\mathrm{O} 1 s$ electron core level changes in the XPS spectra (Fig. 1) reveal a multiplicity of $\mathrm{Ti}$ oxidation states between $\mathrm{Ti}^{1+}$ to $\mathrm{Ti}^{4+}$, stabilizing at $\mathrm{Ti}^{4+}$ for $x \sim 2$. As expected, the metallic band located near the Fermi level abruptly decreases, becoming negligible at $x \sim 2$ (Fig. 4). These sudden changes in the XPS and UPS spectra around $\mathrm{P}^{*}$ represent a transition from metal to a wide-gap semiconductor, i.e., material goes from $\mathrm{TiO}_{1.2}$ to $\mathrm{TiO}_{1.8}$.

The abrupt change between $x \sim 1.2$ and $x \sim 1.9$ (curves $g$ and $I$, respectively, Fig. 1) is accompanied by a color change 
from silvery to golden. The silvery aspect is characteristic of plasmon excitation of metals (or highly degenerated semiconductor). We remark that oxygen forms bonds with localized electrons. Therefore, increasing oxygen concentration diminishes the free electron density, shifting the plasmon excitation to lower energies, i.e., suppressing the metallic shiny surface of the material. ${ }^{54}$ This frequency shift has been well established in colloid chemistry, in electrochemical, as well as in pulse radiolysis experiments. ${ }^{55}$

The transition induced by oxygen is accompanied by morphological changes. The Raman spectra and XRD diffractogram show typical results expected in amorphous materials (Figs. 5 and 7). We note, also, that even for some films there are traces of $\mathrm{TiO}$ or rutile (curves $g$ and $j$, Fig. 5). The multiplicity of Ti oxidation states revealed by the XPS spectra suggest that besides inhomogeneous broadening there is also chemical disorder contribution to the bands width. The structureless films growth with oxygen pressures near to $\mathrm{P}^{*}$ are formed by bigger particles than those obtained at lower $\mathrm{P}_{\mathrm{O}_{2}}$ and exhibit open structures (pictures $h$ to $j$ in Fig. 8). The formation of amorphous and structureless films is a consequence of the process commented above in relation to the ripening Ostwalt phenomenon. ${ }^{53}$

The kinetic of the films formation is also dependent on the oxygen pressure. Indeed, the oxygen pressure where the metal to insulating transition takes place strongly influences the material growing, increasing the thickness by $25 \%$ in the $1.2<x<1.8$. On the other hand, for equivalent deposition parameters, an abrupt thickness shrinking at $x \sim 2$ is observed. The thickness augment is consistent with the observed open films morphology (Fig. 8). The thickness shrinking is due to the fact that, in the presence of abundant oxygen in the chamber there are many more possibilities of reactions $\mathrm{Ti}-\mathrm{O}$ on the target. In fact, during the films deposition at relatively high oxygen partial pressures, an intense activity on the Ti target is observed through the chamber window. ${ }^{56}$ Also, the formation of massive clusters $(\mathrm{TiO})_{\mathrm{n}}$ near the target surface implies than an important fraction of species falls down before reaching the substrate ${ }^{57}$ One should be aware that the formation of $(\mathrm{TiO})_{\mathrm{n}}$ clusters requires high energy for breaking $\mathrm{O}=\mathrm{O}$ bonds. Nevertheless, we found evidence of the $\mathrm{Ti}+\mathrm{O}_{2}=\mathrm{TiO}+\mathrm{O}$ reaction from a bright greenish luminescence emitted near the target at high oxygen deposition pressures $\left(\mathrm{P}_{\mathrm{O}_{2}} \geq \mathrm{P}^{*}\right)$. This emission is compatible with the ${ }^{1} \mathrm{~S}_{0}-{ }^{2} \mathrm{D}_{2}$ radiative transition of free $\mathrm{O}$ atoms induced by the blue emission of the $\mathrm{Ar}^{+}$ion beam. It is interesting to note, finally, that the observed greenish glow is similar to that of the austral or boreal aurora. ${ }^{58}$

For $x \sim 2$ all the samples have the same composition, i.e., nearly stoichiometric $\mathrm{TiO}_{2}$ is formed. Nevertheless, one can distinguish two types of materials associated with the oxygen partial pressure used during deposition: (i) when $\mathrm{P}_{\mathrm{O}_{2}}$ slightly exceeds $\mathrm{P}^{*}$, significant changes in the color, thickness, crystallinity, and morphology, are observed and (ii) only morphological changes are evident when $\mathrm{P}_{\mathrm{O}_{2}}$ exceeds $3 \times 10^{-4}$ mbar. The sharp green, purple, and yellow colors observed in samples deposited at $\sim 5.0 \times 10^{-5}$ and 4.0 $\times 10^{-4}$ mbar oxygen pressures correlate with the film thickness decrement from 180 to $100 \mathrm{~nm}$. The analysis of the transmittance spectra of these films, considering refraction index independent on thickness, explains the color variation as consequence of interference phenomena due to thickness changes. We should note, however, that variations in $20 \%$ have been measured for $\mathrm{TiO}_{2}$ films prepared by sol-gel. ${ }^{59}$ Once the sample thickness reaches $\sim 100 \mathrm{~nm}$, the observed pale yellow color is characteristic of $\mathrm{TiO}_{2}{ }^{6,60} \mathrm{~A}$ complete analysis of the optical properties of these films is currently being investigated and will be reported elsewhere.

Above $\mathrm{P}^{*}$, the crystalline structure of the material shows two interesting characteristics. First, at $\mathrm{P}_{\mathrm{O}_{2}} \sim 5 \times 10^{-5}$ mbar, the material is composed solely by rutile. Second, at $\mathrm{P}_{\mathrm{O}_{2}}$ $\geq 1 \times 10^{-4}$ mbar the material is exclusively anatase with intermediate compositions in sample $l$ (Figs. 5-7). This result is unexpected since rutile is the thermodynamically more stable phase of $\mathrm{TiO}_{2}{ }^{13}$ whereas anatase is the phase most frequently found for $\mathrm{TiO}_{2}$ synthesized by sol-gel or hydrothermal routes. ${ }^{18,61,62}$ This result is probably due to interplay between surface energy and size of the anatase nanocrystallites. ${ }^{63}$ The mechanism leading to the patterned structures formed by elongated particles particularly aligned -as in images $o$ and $q$-in Fig. 8 is probably involving oxygen induced reconstruction and rearrangements of subsurface (interstitial) labile $\mathrm{Ti}$ atoms. ${ }^{64}$

The physical reasons leading to the formation of $\mathrm{TiO}_{2}$ rutile presenting crystal domains of $\sim 11 \mathrm{~nm}$ at $\mathrm{P}_{\mathrm{O}_{2}} \sim 5$ $\times 10^{-5}$ mbar is more difficult to understand. These films exhibit less than $\sim 37 \mathrm{~nm}$ diameter background particles joined by columns to particles of $\sim 71 \mathrm{~nm}$ diameter (picture $k$, Fig. 8). The presence of columns suggests that the link between octahedral structures may be through the crystal corners. Additionally, the underneath structure may also be formed by small octahedral domains embedded in a disordered environment.

\section{SUMMARY AND CONCLUSIONS}

The morphology, electronic and crystal structure of $\mathrm{TiO}_{x}(0.3<x<2)$ films grown onto a $\mathrm{Si}$ substrate by ion beam sputtering of a $\mathrm{Ti}$ target in a controlled oxygen atmosphere is reported. In particular, there is a narrow oxygen pressure range $\left(5.09 \times 10^{-5}<\mathrm{P}_{\mathrm{O}_{2}}^{*}<7.99 \times 10^{-5}\right)$ where the material undergoes a metal wide-gap semiconductor transition. This transition is accompanied by important changes in color and thickness of the films.

The results demonstrate that the oxygen partial pressure allows a fine control of the particle size and the properties of the films. Furthermore, $\mathrm{P}_{\mathrm{O}_{2}}$ can be used for tuning the particle size of the $\mathrm{TiO}_{x}$ films by tailoring the surface/bulk particle ratio. Moreover, the particle size influences the formation of the anatase phase by diminishing crystallite surface energy. This is an attractive route to synthesize films for light sensitive $\mathrm{TiO}_{2}$ based devices, such as photoelectrochemical cells,-catalysts, and -chromic windows, where the anatase phase is more efficient.

\section{ACKNOWLEDGMENTS}

The authors are indebted to M. B. de Moraes for the thickness measurements. This work was partially supported 
by Fapesp Project No. 05/53926, ANPCyT Project No. PICT0633973, CONICET Project No. PIP 2533, and UBACyT Project No. X-003. F.A. is CNPq fellow. S.A.B. is member of CONICET. M.C.M. was CAPES/CNPq-IEL NacionalBrazil fellow.

${ }^{1}$ K. N. Rao and S. J. Mohan, J. Vac. Sci. Technol. A 8, 3260 (1990); K. Balasubramanian, X. F. Han, and K. H. Guenther, Appl. Opt. 32, 5594 (1993); W. D. Brown and W. W. Granneman, Solid-State Electron. 21, 837 (1978).

${ }^{2}$ J. Du and K. L. Choy, Solid State Ionics 173, 119 (2004); M. Ferroni, V. Guidi, G. Martinelli, G. Faglia, P. Nelli, and G. Sberveglieri, Nanostruct. Mater. 7, 709 (1996); H. Tang, Sens. Actuators B 26, 71 (1995).

${ }^{3}$ S. H. Jeong, J. K. Kim, B. S. Kim, S. H. Shim, and B. T. Lee, Vacuum 76, 507 (2004); K. Bange, C. R. Otterrnann, O. Anderson, U. Jeschkowski, M. Laube, and R. Feile, Thin Solid Films 197, 279 (1991).

${ }^{4}$ K. S. Yeung and Y. W. Lamb, Thin Solid Films 109, 169 (1983); M. K. Nazeeruddin, A. Kay, I. Rodicio, R. Humphrey-Baker, E. Mueller, P. Liska, N. Vlachopoulos, and M. Graetzel, J. Am. Chem. Soc. 115, 6382 (1993).

${ }^{5}$ Y. X. Leng, J. Y. Chen, H. Sun, P. Yang, G. J. Wan, J. Wang, and N. Huang, Surf. Coat. Technol. 176, 141 (2004).

${ }^{6}$ S. A. Bilmes, P. Mandelbaum, F. Alvarez, and N. M. Victoria, J. Phys. Chem. B 104, 9851 (2000)

${ }^{7}$ F. Bérubé, F. Kleitz, and S. Kaliaguine, J. Phys. Chem. C 112, 14403 (2008).

${ }^{8}$ Q. Xie, Y. L. Jiang, C. Detavernier, D. Deduytsche, R. L. Van Meirhaeghe, G. P. Ru, B. Z. Li, and X. P. Qu, J. Appl. Phys. 102, 083521 (2007).

${ }^{9}$ A. C. van Popta, J. Cheng, J. C. Sit, and M. J. Brett, J. Appl. Phys. 102, 013517 (2007).

${ }^{10}$ A. Karuppasamy and A. Subrahmanyam, J. Appl. Phys. 101, 064318 (2007).

${ }^{11}$ A. Fujishima, T. N. Rao, and D. A. Tryk, Electrochim. Acta 45, 4683 (2000); T. Ibusuki and K. Takeuchi, J. Mol. Catal. 88, 93 (1994); D. Robert and S. Malato, Sci. Total Environ. 291, 85 (2002).

${ }^{12}$ F. Zhang, Z. Zheng, Y. Chen, X. Liu, A. Chen, and Z. Jiang, J. Biomed. Mater. Res. 42, 128 (1998).

${ }^{13}$ U. Diebold, Surf. Sci. Rep. 48, 53 (2003)

${ }^{14}$ A. Fujishima and K. Honda, Bull. Chem. Soc. Jpn. 44, 1148 (1971).

${ }^{15}$ J. H. Carey, J. Lawrence, and H. M. Tosine, Bull. Environ. Contam. Toxicol. 16, 697 (1976)

${ }^{16}$ M. E. Calvo, R. J. Candal, and S. A. Bilmes, Catal. Today 76, 133 (2002).

${ }^{17}$ K. R. Zhu, M. S. Zhang, J. M. Hong, and Z. Yin, Mater. Sci. Eng., A 403, 87 (2005).

${ }^{18}$ H. S. Jung, H. Shin, J. R. Kim, J. Y. Kim, K. S. Hong, and J. K. Lee, Langmuir 20, 11732 (2004); G. Shukla, P. K. Mishra, and A. Khare, J. Alloys Compd. 489, 246 (2010); C. Sima and C. Grigoriu, Thin Solid Films 518, 1314 (2009); M. R. Nunes, O. C. Monteiro, A. L. Castro, D. A Vasconcelos, and A. J. Silvestre, Eur. J. Inorg. Chem. 2008, 961 (2008).

${ }^{19}$ P. Löbl, M. Huppertz, and D. Mergel, Thin Solid Films 251, 72 (1994).

${ }^{20}$ L. J. Meng and M. P. Santos, Thin Solid Films 226, 22 (1993).

${ }^{21}$ K. Okimura, A. Shibata, N. Maeda, K. Tachibana, Y. Noguchi, and K. Tsuchida, Jpn. J. Appl. Phys. 34, 4950 (1995).

${ }^{22}$ P. Zeman and S. Takabayashi, Surf. Coat. Technol. 153, 93 (2002).

${ }^{23}$ B. R. T. Karunagaran, R. Kumar, V. S. Kumar, D. Mangalaraj, S. K. Narayandass, and G. M. Rao, Mater. Sci. Semicond. Process. 6, 547 (2003).

${ }^{24}$ I. Djerdj, A. M. Tonejc, M. Bijelic, V. Vraneša, and A. Turkovic, Vacuum 80, 371 (2005).

${ }^{25}$ X. Wang, F. Zhang, Z. Zheng, Ch. Li, L. Chen, H. Wang, and X. Lui, Mater. Lett. 44, 105 (2000).

${ }^{26}$ C. A. Figueroa, E. Ochoa, and F. Alvarez, J. Appl. Phys. 94, 2242 (2003).

${ }^{27}$ C. A. Figueroa, D. Wisnivesky, P. Hammer, R. G. Lacerda, R. Droppa, Jr., F. C. Marques, and F. Alvarez, Surf. Coat. Technol. 146-147, 405 (2001). ${ }^{28}$ H. R. Kaufman, J. Vac. Sci. Technol. 15, 272 (1978).
${ }^{29}$ W. Ensinger, Surf. Coat. Technol. 99, 1 (1998).

${ }^{30}$ P. Hammer, N. M. Victoria, and F. Alvarez, J. Vac. Sci. Technol. A 16, 2941 (1998)

${ }^{31}$ R. Jenkins and R. L. Snyder, in Introduction to X-Ray Powder Diffractometry, Chemical Analysis: A Series of Monographs on Analytical Chemistry and Its Applications Vol. 138 (Wiley, New York, 1996).

${ }^{32}$ P. J. Feibelman and D. E. Eastman, Phys. Rev. B 10, 4932 (1974).

${ }^{33} \mathrm{~L}$. Ley, The Physics of Hydrogenated Amorphous Silicon II, Topics in Applied Physics Vol. 56 (Spring-Verlag, Berlin, 1984).

${ }^{34}$ D. A. Shirley, Phys. Rev. B 5, 4709 (1972).

${ }^{35}$ J. H. Scofield, J. Electron Spectrosc. Relat. Phenom. 8, 129 (1976).

${ }^{36}$ F. Carley, G. Spoto, P. R. Chalker, J. C. Riviere, and M. W. Roberts, J. Chem. Soc., Faraday Trans. 1 83, 351 (1987).

${ }^{37}$ J. Pouilleau, D. Devilliers, H. Groult, and P. Marcus, J. Mater. Sci. 32, 5645 (1997).

${ }^{38}$ T. S. Yang, C. B. Shiu, and M. S. Wong, Surf. Sci. 548, 75 (2004).

${ }^{39}$ P. M. Kumar, S. Badrinarayanan, and M. Sastry, Thin Solid Films 358, 122 (2000).

${ }^{40}$ D. Briggs and M. P. Seah, Practical Surface Analysis: Auger and X-ray Photoelectron Spectroscopy, 2nd ed. (Wiley, New York, 1996), Vol. 1.

${ }^{41}$ V. E. Henrich, Rep. Prog. Phys. 48, 1481 (1985).

${ }^{42}$ V. E. Henrich and P. A. Cox, The Surface Science of Metal Oxides (Cambridge University Press, Great Britain, 1994).

${ }^{43}$ R. H. Tait and R. V. Kasowski, Phys. Rev. B 20, 5178 (1979).

${ }^{44} \mathrm{R}$. Hoffmann, Solids and Surfaces: A Chemist's View of Bonding in Extended Structures (VCH, New York, 1988).

${ }^{45}$ T. D. Robert, L. D. Laude, V. M. Geskin, R. Lazzaroni, and R. Gouttebaron, Thin Solid Films 440, 268 (2003).

${ }^{46}$ G. Busca, G. Ramis, J. M. Gallardo Amores, V. Sanchez Escribano, and P. Piaggio, J. Chem. Soc., Faraday Trans. 90, 3181 (1994).

${ }^{47}$ J. Y. Zhang, I. W. Boyd, B. J. O'Sullivan, P. K. Hurley, P. V. Kelly, and J. P. Sénateur, J. Non-Cryst. Solids 303, 134 (2002).

${ }^{48}$ T. Busani and R. A. B. Devine, Semicond. Sci. Technol. 20, 870 (2005).

${ }^{49}$ V. G. Erkov, S. F. Devyatova, E. L. Molodstova, T. V. Malsteva, and U. A. Yanovskii, Appl. Surf. Sci. 166, 51 (2000).

${ }^{50}$ V. E. Henrich, G. Dresselhaus, and H. J. Zeiger, Phys. Rev. B 17, 4908 (1978).

${ }^{51}$ W. Göpel, G. Rocker, and R. Feierabend, Phys. Rev. 28, 3427 (1983).

${ }^{52}$ P. B. Amama, C. L. Pint, L. Mc Jilton, S. M. Kim, E. A. Stach, P. T. Murray, R. H. Hauge, and B. Maruyama, Nano Lett. 9, 44 (2009).

${ }^{53}$ B. Bouchet-Fabre, A. Fadjie Djomkam, M. Delmas, C. Jin, O. Antonin, M. C. Hugon, M. F. Mayne-L'Hermite, F. Alvarez, and T. Minéa, Carbon 47, 3424 (2009).

${ }^{54}$ B. G. Gokhale, S. Rai, and S. D. Rai, J. Phys. F: Met. Phys. 7, 299 (1977).

${ }^{55}$ M. C. Marchi, S. A. Bilmes, and G. M. Bilmes, J. Colloid Interface Sci. 218, 112 (1999); P. Mulvaney, Langmuir 12, 788 (1996).

${ }^{56}$ A. B. R. Kumar, S. Uthanna, B. S. Naidu, and P. S. Reddy, J. Indian Inst. Sci. 81, 573 (2001).

${ }^{57}$ In these working conditions abundant dust is deposited in the chamber bottom.

${ }^{58}$ C. Nicolaides, O. Sinanoglu, and P. Westhaus, Phys. Rev. A 4, 1400 (1971); D. Kella, L. Vejby-Chistensen, P. J. Johnson, H. B. Pedersen, and L. H. Andersen, Science 276, 1530 (1997); S. L. Guberman, ibid. 278, 1276 (1997)

${ }^{59}$ M. Sreemany and S. Sen, Mater. Phys. and Chem. 83, 169 (2004).

${ }^{60}$ P. B. Smith and S. L. Bernasek, Surf. Sci. 188, 241 (1987).

${ }^{61}$ C. J. Barbé, F. Arendsen, P. Comte, M. Jirousek, F. Lenzmann, V. Shklover, and M. Grätzel, J. Am. Ceram. Soc. 80, 3157 (1997).

${ }^{62}$ J. Yang, S. Mei, and J. M. F. Ferreira, J. Am. Ceram. Soc. 83, 1361 (2000); B. L. Bischoff and M. A. Anderson, Chem. Mater. 7, 1772 (1995).

${ }^{63}$ A. S. Barnard and P. Zapol, Phys. Rev. B 70, 235403 (2004); M. R. Ranade, A. Navrotsky, H. Z. Zhang, J. F. Banfield, S. H. Elder, A. Zaban, P. H. Borse, S. K. Kulkarni, G. S. Doran, and H. J. Whitfield, Proc. Natl. Acad. Sci. U.S.A. 99, 6476 (2002).

${ }^{64}$ M. Li, W. Hebenstreit, U. Diebold, M. A. Henderson, and D. R. Jennison, Faraday Discuss. 114, 245 (1999). 